\title{
ОБ АНАЛИЗЕ НАПРАВЛЕНИЙ ВЛИЯНИЯ COVID-19 НА МЕЖДУНАРОДНЫЙ ФИНАНСОВЫЙ МЕНЕДЖМЕНТ
}

\section{(c) 2021 Каржанова Наталья Викторовна}

кандидат филологических наук, доцент кафедры иностранных языков

Российский экономический университет имени Г. В. Плеханова, Россия, Москва

E-mail: Karzhanova.NV@rea.ru

\section{(c) 2021 Забазнова Наталья Михайловна}

старший преподаватель кафедры иностранных языков

Российский экономический университет имени Г. В. Плеханова, Россия, Москва

E-mail:nmzabaznova@gmail.com

\section{(C) 2021 Мурадова Ирина Юрьевна}

старший преподаватель кафедры иностранных языков

Российский экономический университет имени Г.В.Плеханова, Россия, Москва

E-mail: gryad@mail.ru

\section{(c) 2021 Никитин Артём Сергеевич}

студент факультета Международной школы бизнеса и мировой экономики

Российский экономический университет имени Г. В. Плеханова, Россия, Москва

E-mail: tema220163@gmail.com

Статья авторов затрагивает вопросы анализа направлений влияния Covid-19 на международный финансовый менеджмент. Объектом исследования выступает - международный финансовый менеджмент, а предметом - направления влияния на него пандемии Covid-19. Теоретическое значение исследования заключено в развитии теории и методологии взаимного анализа многофакторных динамических систем. Также теоретическое значение исследования проявляется расширением представлений об локальном анализе в условиях неопределенности внешней среды. Практическое и прикладное значение исследования заключены в систематизации и количественном трассировании направлений влияния Covid-19 на международный финансовый менеджмент в глобальной системе координат. Полученные результаты исследования на практике могут быть также применены в целях решения вопросов сферы менеджмента и экономики.

Ключевые слова: проблемы, направления, анализ, решения, влияние, пандемия, Covid-19, международный финансовый менеджмент.

Пандемия Covid-19, вот уже практически два года развивающаяся на глобальном уровне, наносит значительный ущерб всем без исключения сферам человеческой деятельности. Так, по данным Всемирной организации здравоохранения, на начало декабря 2021 года подвергнуты заражению патогенным вирусом во всем мире были более 250000000 людей [6].

Возникновение новых штаммов вируса («дельта», «омикрон»), а также недостаточный уровень образования [2, с. 50] и вакцинации населения во многих странах мира негативным образом сказываются на скорости распространения чрезвычайно опасной болезни, приводя к целому комплексу негативных последствий на глобальном уровне.
В числе сфер жизнедеятельности человека, значительно пострадавших от влияния Covid-19 [5, с. 83] можно выделить: финансы [1, с. 250], производство, социум, медицина. Значения рангов (оценены по исследуемому уровню в единицах от 0 до 100) влияния вируса на приведенные выше сферы в глобальном аспекте на начало 2021 года во всем мире отражены на рисунке 1.

Из рисунка мы можем увидеть, что среди сфер, наиболее пострадавших от пандемии коронавируса можно выделить финансовую (значение ранга на анализируемую дату составляет 75 единиц) и производственную (значение ранга на анализируемую дату составляет 69 единиц). При этом ущерб в других рассматриваемых сферах также остается весьма значительным. 
Для понимания динамической составляющей влияния коронавируса на одну из самых проблемных сфер [3, 4] в глобальном аспекте в 2020 году с поквартальной разбивкой рассмотрим рисунок 2.

Данные рисунка 2 свидетельствуют о наличии четкой положительной динамики роста ранга влияния коронавируса на анализируемую сферу (от 12 единиц в конце 1 квартала до 75 единиц в конце 4 квартала) за весь 2020 год.

Рост показателя происходил поступательно и составил:

- 2 квартал по отношению к 1: 3,17 раз;

- 3 квартал по отношению ко 2: 1,34 раза;

- 4 квартал по отношению к 3: 1,47 раз.
Совокупный рост значения рангов влияния коронавируса на финансовую сферу жизнедеятельности человека в 2020 году составил: 6,25 единицы. Уровень сбалансированности распределения значений по итогам указанного года приблизился к 98,56\%.

Прогнозное значение ранга влияния коронавируса на финансовую сферу жизнедеятельности человека в глобальном аспекте на начало 2022 года приведено на рисунке 3.

Как можно увидеть, на начало 2022 года ранг влияния коронавируса на финансовую сферу жизнедеятельности человека может составить 87 единиц или в 1,16 раз больше, чем на начало 2021 года. Вероятность полученного прогноза

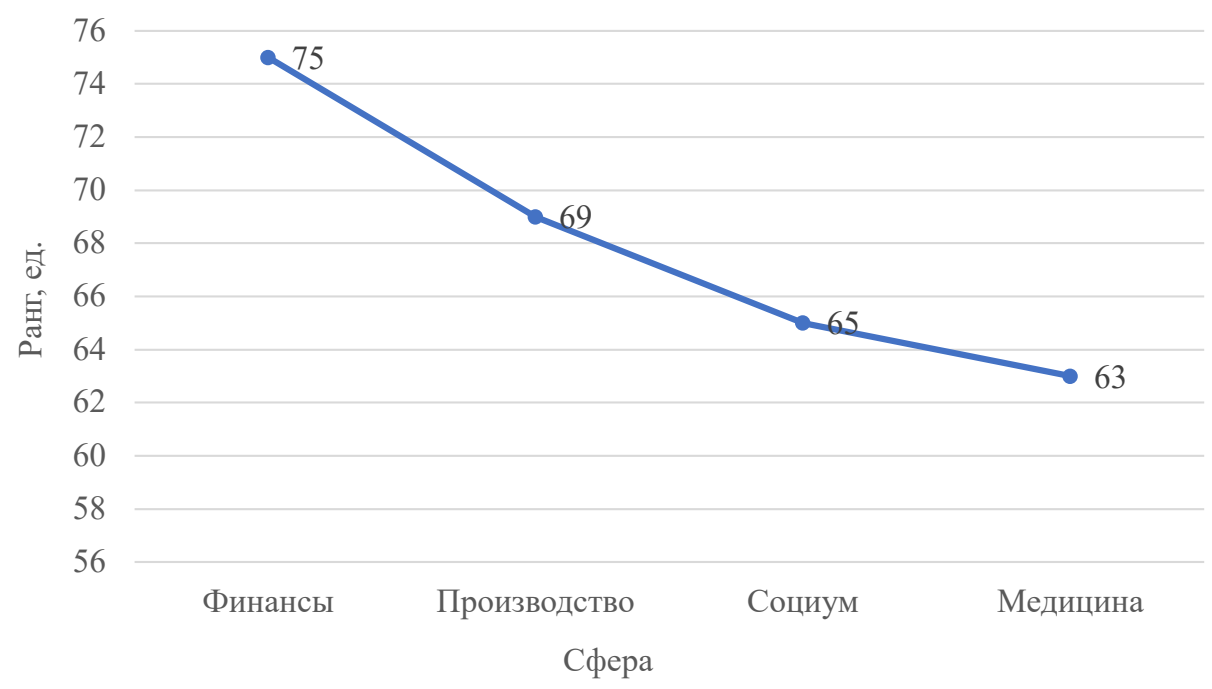

Pис. 1. Значения рангов влияния коронавируса на некоторые сферы жизнедеятельности человека в глобальном аспекте на начало 2021 года, ед. [7]

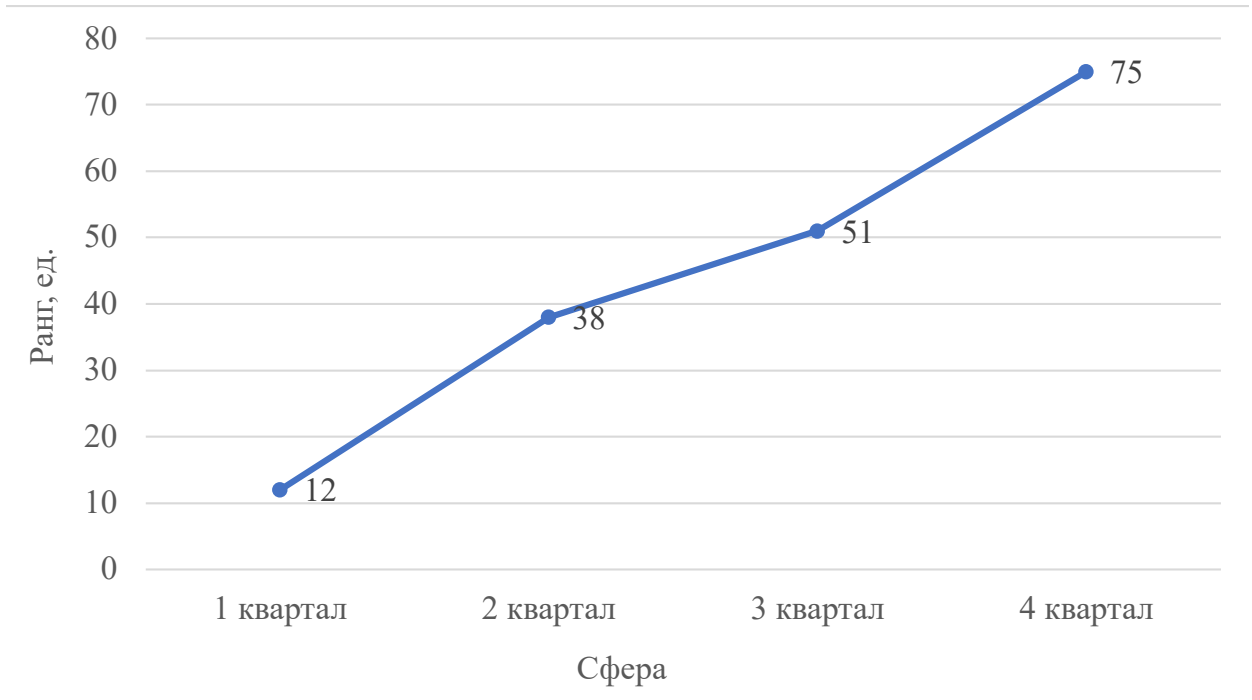

Puc. 2. Значения рангов влияния коронавируса на финансовую сферу жизнедеятельности человека в глобальном аспекте в 2020 году с поквартальной разбивкой (данные приведены на конец каждого квартала), ед. [7] 


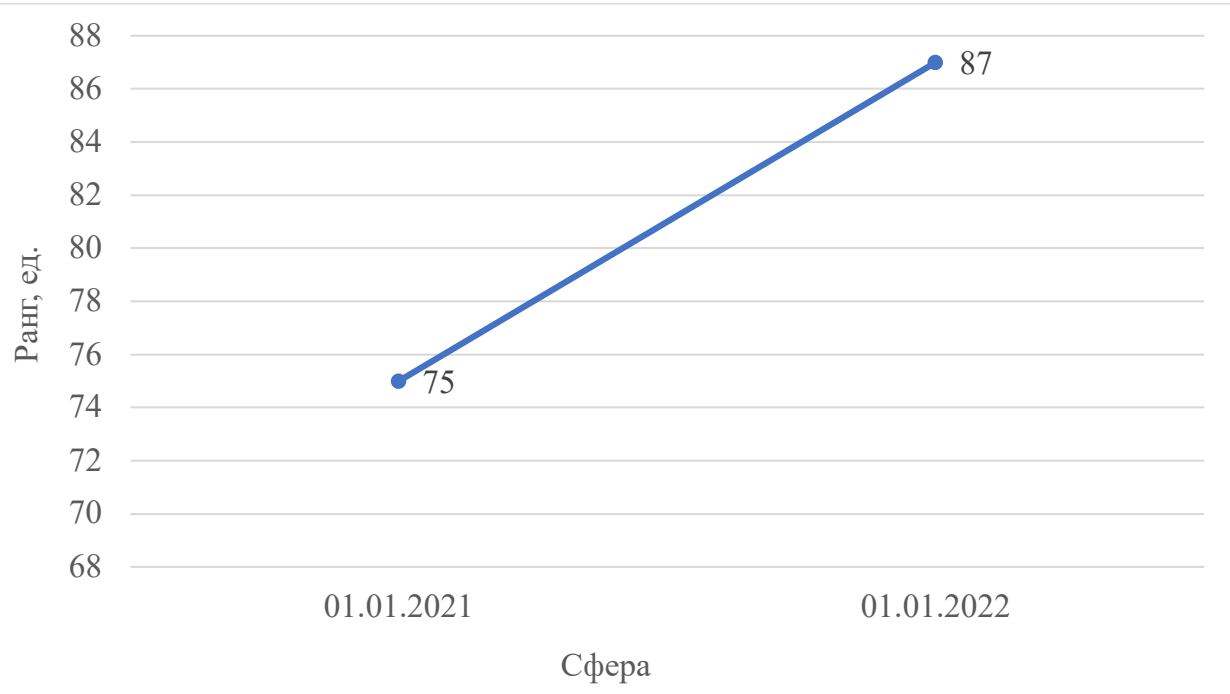

Puc. 3. Прогнозное значение ранга влияния коронавируса на финансовую сферу жизнедеятельности человека на начало 2022 года в сравнении с фактическими данными на начало 2021 года, ед. [7]

составляет 98,37 процента. То есть, с большой уверенностью можно сказать, что проблемы в мировой финансовой сфере усилятся, и в 2022 году будут требовать к себе повышенного внимания по всем связанным с ней актуальным компонентам.

В целях данного исследования были выявлены, систематизированы и проанализированы направления влияния Covid-19 на один из актуальных компонентов, связанных с мировой сферой финансов - международный финансовый менеджмент.

Состав и содержание данных направлений, актуальных на начало 2021 года приведены в таблице 1.

Анализ направлений был осуществлен в форме определения их значимости на выбранную дату в глобальном мировом пространстве. Результаты проведения данного анализа коллективом авторов на начало 2021 года приведены на рисунке 4.

Из рисунка можно увидеть, что наибольшее влияние на международный финансовый менеджмент на начало 2021 года оказывал объем доступных для управления финансовых ресурсов (значимость данного направления составила 43,12 процентов). Чуть меньшая значимость, определенная на уровне 29,37 процентов, приходилась на направление, связанное с оперативностью принимаемых управленческих решений. При этом совокупная значимость направлений

Таблица 1. Состав и содержание направлений влияния Covid-19 на международный финансовый менеджмент на начало 2021 года

\begin{tabular}{|l|l|}
\hline \multicolumn{1}{|c|}{ Наименование направления } & \multicolumn{1}{|c|}{ Содержание направления } \\
\hline $\begin{array}{l}\text { Объем доступных для управления } \\
\text { финансовых ресурсов }\end{array}$ & $\begin{array}{l}\text { С начала возникновения пандемии объем доступных для управления } \\
\text { финансовых ресурсов (практически во всех странах: как развитых, так } \\
\text { и развивающихся) был достаточно волатильным, с тенденцией к сокра- } \\
\text { щению на один объект управления }\end{array}$ \\
\hline $\begin{array}{l}\text { Оперативность принимаемых } \\
\text { управленческих решений }\end{array}$ & $\begin{array}{l}\text { С начала возникновения пандемии средний уровень оперативности } \\
\text { принимаемых финансовых решений (в первую очередь для разви- } \\
\text { вающихся стран) по причине повышения уровня неопределенности } \\
\text { внешней среды снизился }\end{array}$ \\
\hline $\begin{array}{l}\text { Качество принимаемых управлен- } \\
\text { ческих решений }\end{array}$ & $\begin{array}{l}\text { С начала возникновения пандемии средний уровень качества прини- } \\
\text { маемых финансовых решений (для развитых и развивающихся стран } \\
\text { в разной пропорции в зависимости от квартала) по причине значитель- } \\
\text { ного увеличения количества стрессовых ситуаций снизился }\end{array}$ \\
\hline $\begin{array}{l}\text { Скорость принятия управленче- } \\
\text { ских решений }\end{array}$ & $\begin{array}{l}\text { С начала возникновения пандемии средняя скорость принятия управ- } \\
\text { ленческих решений (практически для всех стран, с незначительным } \\
\text { превалированием развивающихся) по совокупности значимых для } \\
\text { рынка причин (в частности, кадрового дефицита и проблем со здоро- } \\
\text { вьем сотрудников) существенно снизилась }\end{array}$ \\
\hline
\end{tabular}




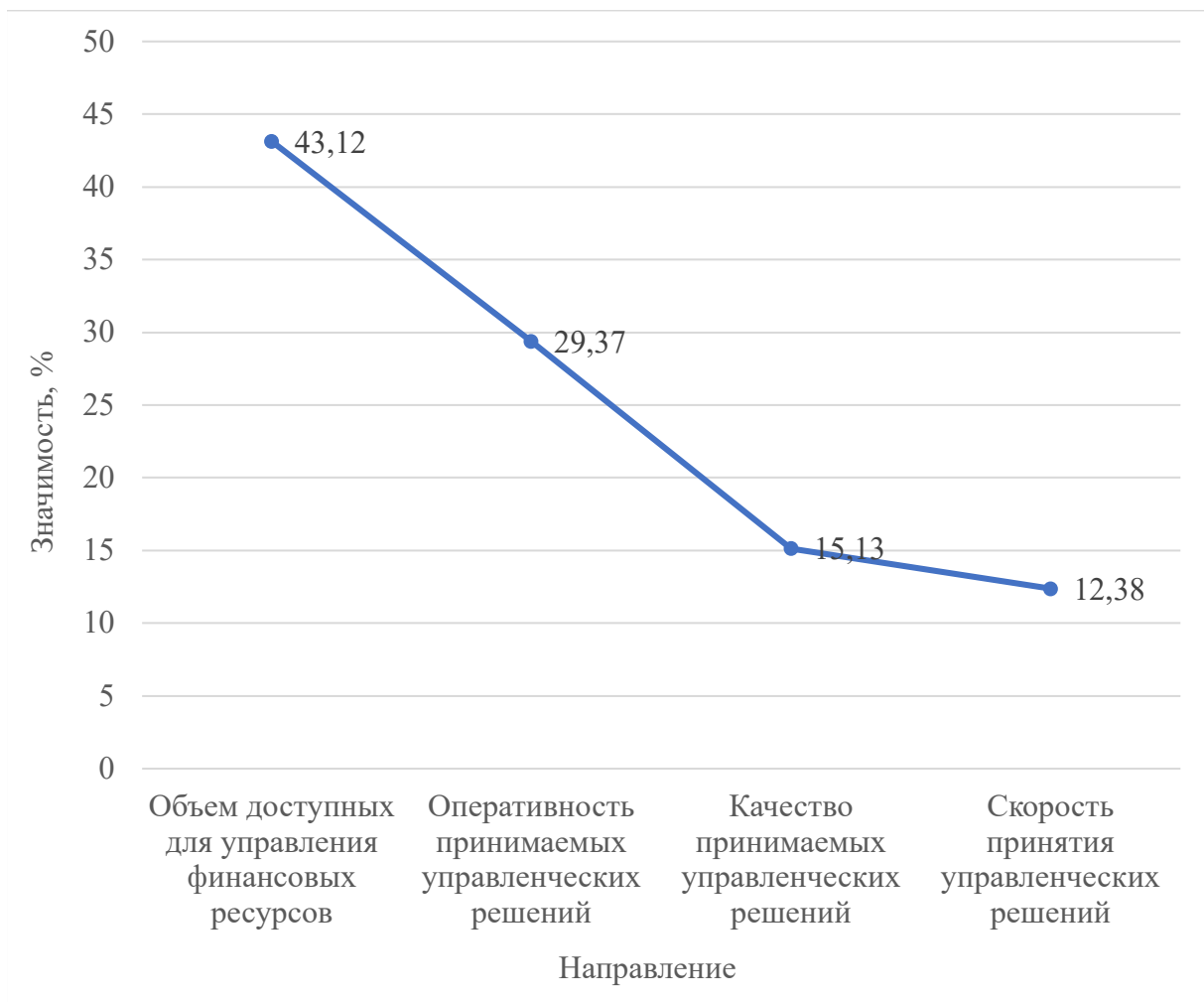

Puc. 4. Определенная значимость влияния Covid-19 на международный финансовый менеджмент в глобальном мировом пространстве на начало 2021 года

в рамках качества и скорости принимаемых управленческих решений не превышала 28 процентов.

Таким образом, можно отметить, что глобальная пандемия, вызванная Covid-19, оказала существенное влияние на многие сферы жизнедеятельности человечества, наиболее актуальной из которых на начало 2021 года была финансовая, формализованная в том числе, проекцией международного финансового менеджмента.

Основными направлениями влияния Covid-19 на международный финансовый менеджмент стали:

- объем доступных для управления финан- совых ресурсов;

- оперативность принимаемых управленческих решений;

- качество принимаемых управленческих решений;

- скорость принятия управленческих решений.

Наиболее высокий из определенных, по уровню значимости, приоритет имел место для первого из обозначенных направлений, значительно превышая три прочих. Именно поэтому, по мнению авторов, в будущем необходимо сосредоточиться на решении проблемы доступности финансовых ресурсов в глобальном масштабе.

\section{Библиографический список}

1. Димитров К. Глобальные риски мировой экономики в условиях пандемии коронавируса / К. Димитров / Экономические науки - Москва: Изд-во: «ООО «24 Принт», 2021. - № 3. - С. 250-254.

2. Долгова Е. Г., Казимирова И. С. и др. К вопросу развития глобальных (транснациональных) университетов в проекции перспектив и рисков высшего образования в Российской Федерации / Е.Г.Долгова, И.С. Казимирова, Ю.А. Кузнецова, Е.А.Николаева / Экономические науки - Москва: Изд-во: «ООО «24 Принт», 2021. - № 2. - C. 49-52.

3. Моисеев Р. В., Белухин В.В. Международный финансовый менеджмент в практике российских и китайских компаний / Р. В. Моисеев, В.В.Белухин / Modern science - Москва: Изд-во: «Научно-информационный издательский центр «Институт стратегических исследований», 2021. - № 1-2. - С. 78-81. 
4. Николаева Е. А., Воейкова А.А. и др. Проблемы высшего образования в Российской Федерации в условиях цифровой глобализации / Е.А.Николаева, А.А. Воейкова, Н. В. Каржанова, М. В. Минова / Экономические науки - Москва: Изд-во: «ООО «24 Принт», 2021. - № 6. - С. 48-51.

5. Шевчук B.О. Анализ мировой экономики в условиях пандемии Covid-19 / В. О.Шевчук / Студенческий форум - Москва: Изд-во: ООО «Международный центр науки и образования», 2021. - № 2-3. - С. 83-87.

6. Всемирная организация здравоохранения [Электронный ресурс]: Статистика заболеваемости в мире Официальный сайт Всемирной организации здравоохранения, 2021. - Режим доступа: https://www.who. int/ru

7. Международный валютный фонд [Электронный ресурс]: Мировая статистика и аналитика по Covid-19Официальный сайт Международного валютного фонда, 2021. - Режимдоступа: https://www.imf.org/en/Home 